CORRESPONDENCE.

\title{
ON THE VALUATTON OF PREMIUMS.
}

To the Editor of the Journal of the Institute of Actuaries.

SIR,-In a letter in the last number of the Journal of the Institute, Mr. James Chatham discusses the question of the average date on which the premiums valued are assumed to fall due. After mentioning various methods of adjusting the account to allow for the unequal distribution of payments throughout the year, he proceeds to point out that, in consequence of the days of grace and the delay of agents in remitting, nearly two months elapse before the premiums are actually received by the office. He then says, "The reserve, "therefore, ought to be increased by, roughly speaking, two months" "premium income." This conclusion appears to be erroneous, as it assumes that the delay in payment at the head office is equivalent to the postponement of the due date for two months. Of course, this is not so, as in the event of death during that period the premium is payable, and the only loss caused by the delay is a small one consisting of interest.

I am, Sir,

Your obedient servant,

11 Lombard Street, E.C.

T. G. C. BROWNE.

16 October 1893.

To the Editor of the Journal of the Institute of Actuaries.

SIR,-My attention has been drawn to a letter from Mr. C. D. Higham (J.I.A., xxvi, 478), in which he mentions the point I referred to in the letter you were good enough to insert in your last issue. He there suggests " that claim acceleration reserve should be " based on the theoretical instead of on the actual date for payment, "at any rate as long as the fraction combined with the annuity-value " in capitalizing future premiums is dependent on the date of their "falling due rather than of their being received." This method bas certainly the merit of consistency, but I am not aware of its ever having been adopted by any office. 
I take this opportunity of giving the formula I propose should be used for finding the addition to be made to the reserve to provide for the loss of two months' interest on the premiums, in order to remove any misapprehension my former letter may have created. Assuming the claims are paid on proof of death and title, and that the adjustment for this is an addition of (say) four months' interest to the reserve calculated in the usual way, the formula I propose is

$$
\frac{i}{6} \Sigma \mathrm{P}\left(1+\frac{i}{3}\right)(k+a),
$$

where $k$ is the fraction used in the valuation. The formula can easily be adjusted to suit any other circumstances. Applying it to the case I supposed, the addition to the reserve would be about $£ 15,000$. It will be seen, therefore, that it is not so large as the addition for payment of claims upon proof of death and title, but I think it is sufficiently large to justify special provision being made for it.

$$
\begin{aligned}
& \text { I am, Sir, } \\
& \text { Your obedient servant, }
\end{aligned}
$$

Edinburgh, JAMES CHA'THAM.

21 October 1893.

\section{CONSUMPTIVE FAMILY HISTORY.}

To the Editor of the Journal of the Institute of Actuaries.

SIr,-A brief reply seems called for from me to Mr. Macaulay's letter in the last number of the Journal. He rightly describes the principle upon which the Mutual cases having a consumptive family history were selected, quoting Mr. Manly's words as follows: "supposing that case were to come before you to-day, would you consider the cause of death thus recorded to be primarily consumption."

In making the selection, I chose only those cases which all medical men would be agreed to consider as consumption, such as decline, chronic pneumonia in a young subject, \&c.; so that the results of the Mutual investigation are quite free from any personal judgment. It was not in any case taken for granted that childbirth recorded as the cause of death indicated consumption, nor is it my opinion that in a large proportion of cases it does so, as Mr. Macaulay appears to think.

Childbirth in family history is rightly, I believe, considered as consumption when no further information is forthcoming as a precautionary measure simply; enquiry will usually clear up these cases, and a certain small proportion of them will turn out to be really consumption.

London, Yours truly,

23 December 1893.

THOS. GLOVER LYON, M.D. 